\title{
ANTIEPILEPTIC DRUGS, REACTION TIME, AND IMPULSIVITY
}

The effects of antiepileptic drugs (AED) on reaction time, attention, and impulsivity in 111 epileptic children, aged 5 to 13 years, are reported from the Children's Hospital of Los Angeles and University of Southern California School of Medicine. Higher total serum levels of AEDs correlated significantly with more impulsive errors. Carbamazepine (CBZ) monotherapy levels in 54 children were negatively correlated with simple and complex reaction times and omission errors, and positively correlated with commission errors; higher serum levels were associated with faster responses and fewer omission errors but impulsive errors on complex reaction time tests were increased. Among 73 children receiving phenobarbital monotherapy, minimal slowing of reaction times and increased omission errors were noted with higher serum levels, but changes were not significant. A number of other AEDs were included in the total drug score analysis, but none was large enough to analyze individually as monotherapy, except for phenobarbital and CBZ. (Mitchell WG et al. Effects of antiepileptic drugs on reaction time, attention, and impulsivity in children. Pediatrics Jan 1993; 91: 101-105). (Reprints: Wendy G Mitchell MD, Neurology, Mail Stop 82, Children's Hospital of Los Angeles, PO Box 54700, Los Angeles, CA 90054).

COMMENT. Contrary to recent concern regarding possible adverse effects of phenobarbital on cognitive function, this study shows no significant effects on reaction time and attention. The authors do not recommend $\mathrm{CBZ}$ in preference to other AEDs.

\section{ANGELMAN SYNDROME AND EPILEPSY}

Characteristic epileptic seizures and EEG abnormalities are reported in

three siblings with Angelman syndrome from the Kansai University Otokoyoma Hospital, Kyoto; and the Nagasaki University School of Medicine, Japan. Seizures were generalized, and interictal EEG findings included 2- to 3$\mathrm{Hz}$ high-voltage slow waves bioccipitally and sporadic slow spike wave complexes bifrontally. EEG minor epileptic status occurred in a 38 month old sib and was responsive to clonazepam. The thresholds of wave $\mathrm{V}$ in auditory brainstem responses were increased, and the latency of wave I was prolonged in all 3 siblings. Chromosome studies were normal, but DNA deletion of the GABA receptor subunit gene was reported (Saitoh $S$ ) in the maternal grandfather, mother, and 3 siblings. (Sugimoto $T$ et al. Angelman syndrome in three siblings: Characteristic epileptic seizures and EEG abnormalities. Epilepsia_Nov/Dec 1992; 33: 1078-1082). (Reprints: Dr T Sugimoto, Department of Pediatrics, Kansai Medical University Otokoyama Hospital, Izumi 19, Otokoyama, Yawatashi, Kyoto, 614 Japan).

COMMENT. Angelman syndrome is characterized by brachycephaly, microcephaly, mental retardation, jerky puppet-like movements of 